\title{
Cetuximab plus oxaliplatin/leucovorin/5-fluorouracil in first-line metastatic gastric cancer: a phase II study of the Arbeitsgemeinschaft Internistische Onkologie (AIO)
}

\author{
F Lordick ${ }^{*, 1}$, B Luber ${ }^{2}$, S Lorenzen', S Hegewisch-Becker ${ }^{3}$, G Folprecht ${ }^{4}$, E WöII ${ }^{5}$, T Decker ${ }^{6}$, E Endlicher ${ }^{7}$, \\ N Röthling ${ }^{8}$, T Schuster', G Keller ${ }^{2}$, F Fend ${ }^{2,10}$ and C Peschel'
}

'Klinikum rechts der Isar, 3rd Medical Department, Technische Universität München, Ismaninger Straße 22, 8I 675 Munich, Germany; ${ }^{2}$ Institute of Pathology, Technische Universität München, Ismaninger Straß22, 81675 Munich, Germany; ${ }^{3}$ Onkologische Schwerpunktpraxis Eppendorf, Eppendorfer Landstr. 42, 20249 Hamburg, Germany; ${ }^{4}$ Ist Medical Department, Universitätsklinik Carl Gustav Carus, Fetscherstr.74, 01 307 Dresden, Germany; ${ }^{5}$ Medical Department, Klinik St. Vinzenz, Sanatoriumstrasse, 65 II Zams, Austria; ${ }^{6}$ Onkologische Schwerpunktpraxis, Wilhelm-Hauff-Str. 41 , 882 I 4 Ravensburg, Germany; ${ }^{7}$ Ist Medical Department, Klinikum der Universität, Franz-Josef-Strauss-Allee 11, 93053 Regensburg, Germany; ${ }^{8}$ Munich Centre for Clinical Studies, Ismaninger Straße 22, 81675 Munich, Germany; ${ }^{9}$ Institute of Medical Statistics and Epidemiology, Technische Universität München, Ismaninger Straße 22, 8/ 675 Munich, Germany; ${ }^{10}$ Institute of Pathology, Eberhard-Karls-Universität, Liebermeisterstraße 8, 72076 Tübingen, Germany

BACKGROUND: Cetuximab enhances the efficacy of chemotherapy in several cancer types. This trial assessed the activity of cetuximab and chemotherapy in advanced gastric cancer.

METHODS: Patients with previously untreated, metastatic, gastric cancer received cetuximab $400 \mathrm{mg} \mathrm{m}^{-2}$ at first infusion followed by weekly infusions of $250 \mathrm{mg} \mathrm{m}^{-2}$ combined with FUFOX (oxaliplatin $50 \mathrm{mg} \mathrm{m}^{-2}$, 5-FU $2000 \mathrm{mg} \mathrm{m}^{-2}$, and DL-folinic acid $200 \mathrm{mg} \mathrm{m}^{-2} \mathrm{dl}, 8,15$ and $22 \mathrm{qd} 36$ ). The primary endpoint was tumour response.

RESULTS: Overall, 52 patients were enrolled. The most common grade 3/4 toxicities were diarrhoea (33\%), and skin toxicity (24\%). Efficacy was evaluable in 46 patients who showed a response rate of 65\% (Cl 95\%: 50-79\%) including four complete responses. Time to progression (TTP) was 7.6 months (Cl 95\%: 5.0-10.1 months) and overall survival (OS) was 9.5 months (Cl 95\%: 7.9- II.I months). Epidermal growth factor receptor (EGFR) was detectable in $60 \%$ of tumours but showed no correlation with treatment outcome. A KRAS mutation was found in only I of 32 (3\%) tumour samples analysed.

CONCLUSION: Cetuximab plus FUFOX showed an interesting high response rate in metastatic gastric cancer. Cetuximab plus platinum-fluoropyrimidine chemotherapy is at present being investigated in a phase III randomised controlled trial.

British Journal of Cancer (2010) I 02, 500-505. doi:I0.1038/sj.bjc.660552I www.bjcancer.com

Published online 12 January 2010

(C) 2010 Cancer Research UK

Keywords: antibody; chemotherapy; cetuximab; EGFR; gastric cancer; KRAS mutation

Stomach cancer is the fourth most common cancer worldwide, with 603003 new cases in men and 330290 new cases in women in 2002 (Kamangar et al, 2006). Although current fluorouracil- and platinum-based combination chemotherapy regimens confer a survival benefit to patients with advanced gastric cancer when compared with the best supportive care (Wagner et al, 2006), the outcomes remain suboptimal. Oxaliplatin has been shown to equal the efficacy of cisplatin in this clinical setting (Al-Batran et al, 2008; Cunningham et al, 2008). In a previous trial our study group showed that weekly oxaliplatin plus 5-fluorouracil/folinic acid (FUFOX) has a high activity and an acceptable toxicity profile when used in advanced gastric cancer (Lordick et al, 2005). This led to a broad acceptance of the FUFOX regimen within the Arbeitsgemeinschaft Internistische Onkologie (AIO) study network and investigators felt

\footnotetext{
*Correspondence: Dr F Lordick;

E-mail: f.lordick@klinikum-braunschweig.de

Revised 19 November 2009; accepted 25 November 2009; published online 12 January 2010
}

that FUFOX can serve as a chemotherapy backbone for combination studies with biologically targeted drugs.

Cetuximab is a monoclonal IgG1 antibody directed against the epidermal growth factor receptor (EGFR) (Martinelli et al, 2009). Cetuximab binds to the extracellular domain of EGFR in its inactive configuration and competes for receptor binding by occluding the ligand-binding region. This antibody-receptor interaction prevents receptor dimerisation and thereby blocks ligand-induced EGFR tyrosine kinase activation. Cetuximab also induces EGFR internalisation, downregulation, and degradation. Antibody-dependent cytotoxicity may also contribute significantly to the anticancer activity of cetuximab. By provoking an immune system mediated antitumour response, cetuximab inhibits cancer-cell proliferation (G1 phase arrest), angiogenic growth factor production (VEGF) and tumour-induced angiogenesis, and cancer cell invasion. In preclinical and clinical tumour models cetuximab potentiates the antitumour activity of cytotoxic drugs and radiotherapy (Ciardiello and Tortora, 2008).

In pivotal phase II and phase III studies, cetuximab has shown activity in chemotherapy refractory and chemo-naïve-advanced 
colorectal cancer given in combination with irinotecan- or oxaliplatin-based chemotherapy (Cunningham et al, 2004; Bokemeyer et al, 2009; Van Cutsem et al, 2009), which is in combination with platinum-based chemotherapy in both advanced non-small-cell lung cancer and squamous cell cancer of the head and neck (Vermorken et al, 2008) and in combination with radiotherapy in localised head and neck cancer (Bonner et al, 2006).

Epidermal growth factor receptor has been found to be overexpressed in gastric cancer (Gamboa-Dominguez et al, 2004; Dragovich et al, 2006). Although colorectal tumours with an activating mutation of the Kirsten $(K)$-ras gene are not sensitive to EGFR antibodies (Amado et al, 2008; Karapetis et al, 2008), the incidence of KRAS mutations in gastric cancer appears to be low (Kim et al, 2003; Lee et al, 2003; Zhao et al, 2004).

We carried out a phase II trial to investigate the activity and safety of cetuximab plus weekly FUFOX in patients with metastatic gastric cancer.

\section{PATIENTS AND METHODS}

This multicentre study was conducted at seven institutions in Germany and Austria. It was organised within the study network of the Arbeitsgemeinschaft Internistische Onkologie (AIO) and was coordinated by the Munich centre for clinical studies. The protocol was approved by the ethics committee for human research at the Technische Universität München, Munich, and conformed to the principles of the Declaration of Helsinki and its subsequent amendments. The study has been assigned the European Clinical Trials Database number 2004-004024-12.

\section{Patient characteristics}

Eligibility criteria included the following: histologically confirmed metastatic or locally advanced irresectable adenocarcinoma of the stomach or oesophago-gastric junction; age 18 years or older; Eastern Cooperative Oncology Group (ECOG) performance status $\leqslant 2 ; \geqslant 1$ unidimensionally measurable lesion $\geqslant 1 \mathrm{~cm}$ in diameter detected by computed tomography (CT) scan or magnetic resonance imaging (MRI); cardiac ejection fraction within normal limits; absolute neutrophil count $\geqslant 2000 \mu \mathrm{l}^{-1}$; thrombocyte count $\geqslant 100000 \mu \mathrm{l}^{-1}$; total bilirubin $\leqslant 1.5 \times$ upper limit of normal (ULN) and transaminases $\leqslant 2.5 \times \mathrm{ULN}$; creatinine clearance $>70 \mathrm{ml} \mathrm{min}^{-1}$; no previous malignancy and no chemotherapy except in the adjuvant or neoadjuvant setting $>6$ months before study entry. All patients gave written informed consent.

\section{Treatment}

Cetuximab was administered at an initial dose of $400 \mathrm{mg} \mathrm{m}^{-2}$ on day 1 over $120 \mathrm{~min}$, followed by weekly doses of $250 \mathrm{mg} \mathrm{m}^{-2}$ over $60 \mathrm{~min}$. Oxaliplatin $50 \mathrm{mg} \mathrm{m}^{-2}$ was given i.v. over $120 \mathrm{~min}$ followed by folinic acid $200 \mathrm{mg} \mathrm{m}^{-2}$ i.v. over $120 \mathrm{~min}$ and 5-fluorouracil $2000 \mathrm{mg} \mathrm{m}^{-2}$ i.v. over $24 \mathrm{~h}$ on days $1,8,15$, and 22 , every 5 weeks (one cycle). Treatment continued until best response, or until there was evidence of disease progression, unacceptable toxicity, death, or withdrawal of patient consent. Toxicity was graded according to the National Cancer Institute Common Toxicity Criteria (NCI-CTC, version 3.0).

\section{Evaluation}

Patients were assessed weekly for potential adverse events and disease-related signs and symptoms. Patients who had ended their treatment but had not experienced disease progression were observed every 12 weeks until progressive disease and every 3 months thereafter. Tumour measurements were undertaken every two cycles (10 weeks) and were carried out according to Response Evaluation Criteria in Solid Tumours (RECIST) criteria (Therasse et al, 2000). Best objective responses (primary study endpoint) and confirmed responses were reported.

\section{EGFR expression analysis}

Before randomisation, EGFR expression was evaluated locally from tumour specimens using a standardised immunohistochemistry assay (EGFR pharmDx Dako, Glostrup, Denmark). Positive staining was defined as any membrane staining above background level (defined as the level noted in a negative control sample) in $\geqslant 1 \%$ cancer cells of any intensity: with $1+$ equating to faint or barely perceptible membrane staining, $2+$ indicating weak to moderate staining of the complete cell membrane and $3+$ indicating strong staining of the complete cell membrane.

\section{KRAS mutational analysis}

Screening of tumour DNA for KRAS mutations in codon 12 or 13 was carried out centrally. Before DNA extraction, tumour tissue (frozen or paraffin-embedded) was manually microdissected to assure at least $60 \%$ tumour cell content of the analysed sample. KRAS mutation analysis was carried out by polymerase chain reaction (PCR) amplification of exon 2 and direct sequencing. Primers were modified according to Brink et al (2003). DNA sequencing was carried out using the BigDye Terminator v1.1 Cycle Sequencing Kit (Applied Biosystems, Foster City, CA, USA) and separation of the products using an automated sequencing system (3130 Genetic Analyzer, Applied Biosystems).

\section{Statistical analysis}

The primary study endpoint was the proportion of patients who responded to cetuximab-FUFOX. The study was designed as a two-stage trial assuming a response rate of $\leqslant 30 \%$ as not being of further interest (null hypothesis) and a response rate of $\geqslant 50 \%$ as interesting (alternative hypothesis). The best-observed response was taken as a basis for the determination of primary endpoint and confirmed responses were also reported. The statistical analysis was carried out using SPSS software (version 12.0; SPSS, Chicago, IL, USA). In all, 95\% CIs were calculated for all relevant estimates using StatXact (version 5; Cytel, Cambridge, MA, USA). All statistical analyses were carried out at a $5 \%$ level of significance.

The secondary study endpoints were median overall survival (OS), time to progression (TTP), and toxicity. Analysis of TTP and OS was carried out using the Kaplan-Meier life-table method. Comparisons between groups of patients were made by log-rank test. Median survival and hazard ratios (HR) calculated by Cox's proportional hazards model were reported, with 95\% CIs. TTP and OS were analysed in the intent-to-treat (ITT) population. Time to progression was determined from the day of study assignment to the date of any progression, or last contact. Patients who had not progressed at the time of the final analysis were censored at the date of their last tumour assessment. OS was calculated from the day of assignment to death. Patients alive at the final survival analysis were censored using the last contact date.

\section{RESULTS}

\section{Patient characteristics}

A total of 52 patients were enrolled between April 2005 and March 2006. The primary tumour was located at the oesophago-gastric junction in 25 patients and in other parts of the stomach in the remaining 27 patients. All patients presented with metastatic disease, with the lymph nodes, the liver, the peritoneum, and the lung as the predominant metastatic sites (Table 1). 
Table I Patient and tumour characteristics at baseline

\begin{tabular}{|c|c|c|}
\hline Characteristic & No of patients $(n=52)$ & $\%$ \\
\hline \multicolumn{3}{|l|}{ Age (years) } \\
\hline Median & 63 & \\
\hline Range & $38-80$ & \\
\hline \multicolumn{3}{|l|}{ Gender } \\
\hline Male & 39 & 75 \\
\hline Female & 13 & 25 \\
\hline \multicolumn{3}{|l|}{ ECOG performance status } \\
\hline 0 & 19 & 37 \\
\hline I & 25 & 48 \\
\hline 2 & 8 & 15 \\
\hline \multicolumn{3}{|l|}{ Disease status } \\
\hline Locally advanced & 0 & \\
\hline Metastatic & 52 & 100 \\
\hline \multicolumn{3}{|l|}{ Metastatic sites } \\
\hline Lymph node & 45 & 87 \\
\hline Liver & 23 & 46 \\
\hline Lung & 9 & 17 \\
\hline Peritoneum & 16 & 31 \\
\hline Bone & 4 & \\
\hline Other & 5 & 10 \\
\hline \multicolumn{3}{|l|}{ Site of the primary tumour } \\
\hline Oesophago-gastric junction & 25 & 48 \\
\hline Stomach & 27 & 52 \\
\hline \multicolumn{3}{|l|}{ No. of organs involved } \\
\hline I & 10 & 19 \\
\hline 2 & 20 & 39 \\
\hline$>2$ & 22 & 42 \\
\hline \multicolumn{3}{|l|}{ Previous therapy } \\
\hline Chemotherapy (adjuvant) & 12 & 23 \\
\hline Radiotherapy & 3 & 0 \\
\hline Surgery & 26 & 52 \\
\hline
\end{tabular}

Abbreviation: ECOG = Eastern Cooperative Oncology Group.

\section{Feasibility and safety}

In total, 167 cycles of cetuximab-FUFOX were administered, with a median of two cycles (range $0-8$ ) per patient. The median duration of treatment was 10 weeks (range $0-48$ ). In all, 132 of 167 cycles $(79 \%)$ were given without any delay. At least one dose reduction was carried out in 23 out of 52 patients (44\%) because of adverse events, including reductions for one or both cytotoxic drugs (oxaliplatin and/or 5-fluorouracil) in 21 out of 52 patients $(40 \%)$ and for the antibody cetuximab in 16 out of 52 patients (31\%). The main reasons for dose reductions and delays were diarrhoea, haematological side effects, skin toxicity, and fatiguenausea syndrome.

The study protocol was advised to be continued with treatment until progression. However, 25 patients $(48 \%)$ discontinued the treatment for other reasons. The main reasons for unplanned therapy discontinuation were as follows: therapy-related adverse events or the deterioration of performance status in 11 patients $(21 \%)$, request of the patient or withdrawal of consent in 7 patients (13\%), achievement of a best clinical response in 3 patients $(6 \%)$, secondary resection with no further study treatment after surgery in 2 patients (4\%), and death without documented progression in 2 patients $(4 \%)$. Five patients $(10 \%)$ died within 60 days of study inclusion. The following two deaths were related to treatment: 1 patient died because of a septic shock, which occurred as a result of neutropenic septic diarrhoea; another patient suffered a severe
Table 2 Haematological and non-haematological toxicities (National Cancer Institute Common Toxicity Criteria, Version 3.0)

\begin{tabular}{lccc}
\hline & \multicolumn{3}{c}{ No. of patients (\%) (n=5 I) } \\
\cline { 2 - 4 } Toxicity & Grade I-2 & Grade 3-4 & Total \\
\hline Haematological toxicity & & & \\
Anaemia & $42(82)$ & $0(0)$ & $42(82)$ \\
Neutropenia & $23(45)$ & $3(6)$ & $26(51)$ \\
Febrile neutropenia & - & $3(5)$ & $3(5)$ \\
Thrombocytopenia & $15(29)$ & $1(2)$ & $16(31)$ \\
Non-haematological toxicity & & & \\
Diarrhoea & $26(51)$ & $17(33)$ & $43(84)$ \\
Nausea & $28(54)$ & $3(6)$ & $31(60)$ \\
Emesis & $15(29)$ & $0(0)$ & $15(29)$ \\
Skin toxicity & $33(65)$ & $12(24)$ & $47(89)$ \\
Sensory neuropathy & $33(65)$ & $2(4)$ & $35(69)$ \\
Hand-foot syndrome & $16(31)$ & $3(6)$ & $19(37)$ \\
Asthenia & $30(59)$ & $5(10)$ & $35(69)$ \\
\hline
\end{tabular}

Table 3 Anti-tumour activity (evaluable patients, $n=46$ )

\begin{tabular}{lcr}
\hline Response according to RECIST & No. of patients & $\%$ \\
\hline Overall response rate & 30 & 65 \\
Complete response & 4 & 9 \\
Partial response & 26 & 57 \\
Stable disease & 8 & 17 \\
Progressive disease & 8 & 17 \\
\hline
\end{tabular}

Abbreviation: RECIST = Response Evaluation in Solid Tumours.

infusion-related hypersensitivity reaction during the first infusion of cetuximab. In rapid succession he developed pneumonia and multi-organ failure and died several days after the first infusion of cetuximab. Two patients died because of early disease progression. One patient rapidly developed symptomatic brain metastases, whereas two patients had rapid progression in extracerebral sites.

\section{Toxicity}

Haematological and non-haematological adverse events are summarised in Table 2. Overall, 34 patients $(65 \%$; $95 \%$ CI, $50-76 \%$ ) experienced grade $3 / 4$ adverse events. One patient withdrew consent during the first infusion cycle and is therefore excluded from detailed toxicity analyses. The most important grade $3 / 4$ toxicities were: neutropenia $6 \%$, febrile neutropenia $2 \%$, thrombocytopenia $2 \%$, nausea $6 \%$, diarrhoea $33 \%$, sensory neuropathy $4 \%$, hand-foot-syndrome $6 \%$, and skin-reactions $24 \%$.

\section{Response}

In total, 46 patients were assessable for response according to RECIST criteria. A total of 6 patients were not assessable ( 1 patient died early because of the sequela of an infusion-related reaction, 1 withdrew consent, and 4 patients stopped therapy within the first cycle because of toxicity and were switched to no treatment or other second-line treatment without previous tumour assessment).

The overall response rate (ORR; complete response + partial response) was $65 \%$ (95\% CI, 50-79\%) including 4 complete and 26 partial responses (Table 3 ). In all, 18 responses have been formally confirmed resulting in a confirmed ORR of 39\%. Altogether, 17 out of 22 patients with primary tumours located at the oesophagogastric junction had an objective response (77\%) compared with 13 out of 24 patients (54\%) with primary tumours located in the stomach. 

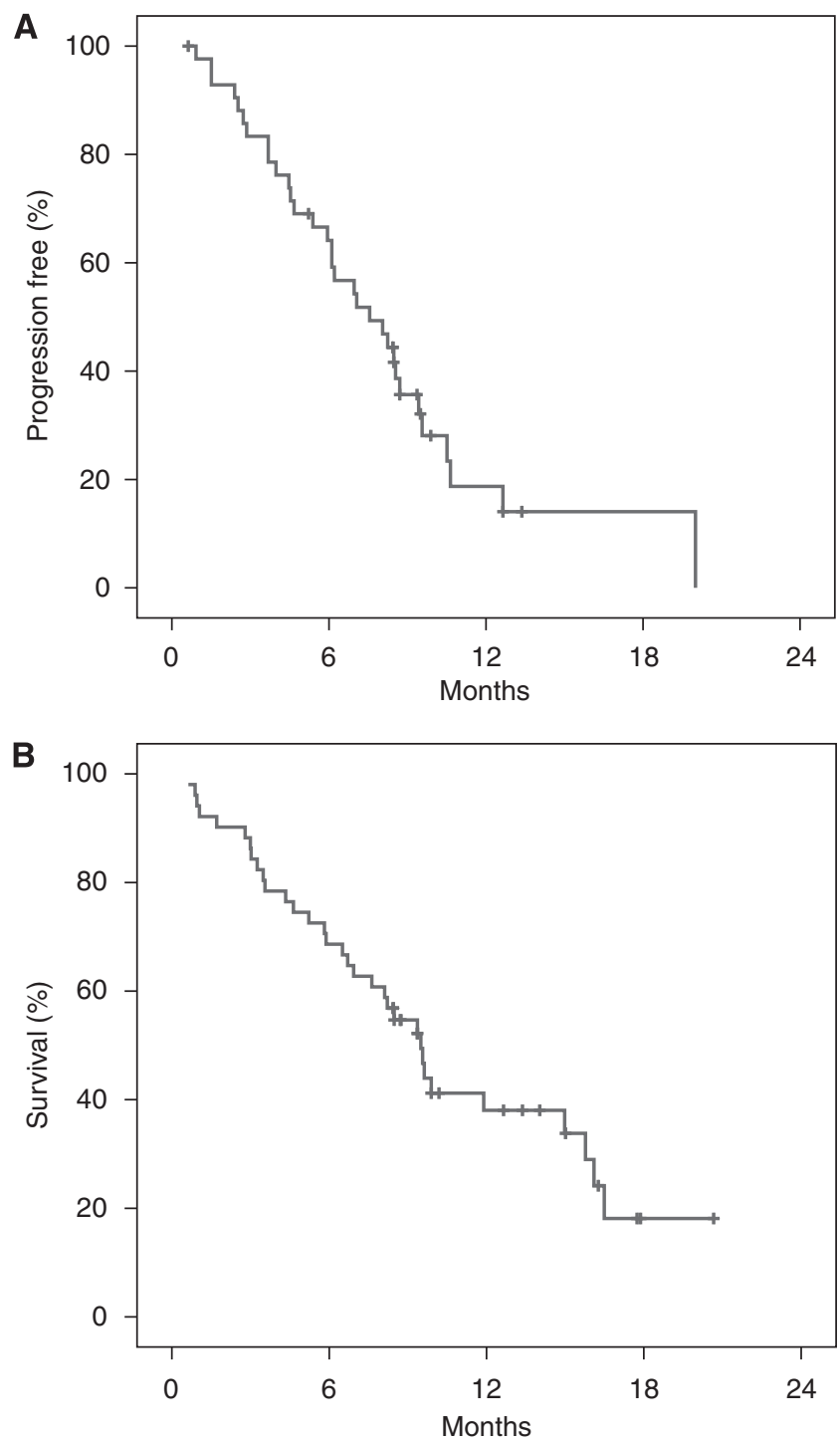

Figure I Kaplan-Meier estimates of (A) time to progression (TTP) and (B) overall survival (OS) among patients with metastatic gastric cancer treated with cetuximab, oxaliplatin, folinic acid, and 5-fluorouracil (FUFOX).

\section{OS and TTP}

At a median follow-up of 18 months, 44 out of 52 enrolled patients (85\%) presented with progressive disease. At the time of this analysis, 18 patients $(35 \%)$ are alive.

The median TTP was 7.6 months (95\% CI: 5.0-10.1 months; Figure $1 \mathrm{~A})$. The probability of remaining progression-free at 1 year was $19 \%$.

The median OS was 9.5 months (95\% CI: 9.7-11.1 months; Figure 1B). The 1-year survival rate for patients with metastatic disease was $37 \%$.

\section{EGFR status and KRAS mutation analysis}

Overall, 42 tumour blocks or slides were available for EGFR analysis and were reviewed centrally at the Institute of Pathology, Technische Universität München. Immunohistochemical EGFR detection was possible in $60 \%$ of these samples. No clear association was found between the detection of EGFR and the response rate (Table 4). Of the 32 samples that were analysed for
Table 4 Clinical outcome according to EGFR immunohistochemistry

\begin{tabular}{lcc}
\hline & $\begin{array}{c}\text { EGFR } \\
\text { detectable }\end{array}$ & $\begin{array}{c}\text { EGFR non- } \\
\text { detectable }\end{array}$ \\
\hline Overall response rate & $54 \%$ & $76 \%$ \\
Clinical benefit rate (CR, PR, and SD) & $79 \%$ & $82 \%$ \\
Median time to progression & 7.0 months & 9.4 months \\
Median overall survival & 8.1 months & 9.9 months \\
\hline
\end{tabular}

Abbreviations: $C R=$ complete response; $E G F R=$ epidermal growth factor receptor; $\mathrm{PR}$, partial response; $\mathrm{SD}=$ stable disease

KRAS mutation, only one mutation, located in the exon 1 region of the KRAS gene, was found.

\section{Post-progression treatment}

Second- or third-line chemotherapy was given to 13 out of 52 patients $(25 \%)$, consisting mainly of irinotecan ( 7 patients) and taxanes ( 3 patients). Three patients received an alternative platinum - fluoropyrimidine-based regimen. Three patients underwent secondary tumour resection in an attempt to achieve a maximum tumour reduction.

\section{DISCUSSION}

Cetuximab, a monoclonal IgG1 antibody has been shown to improve the activity of platinum-based chemotherapy (Vermorken et al, 2008; Bokemeyer et al, 2009). Epidermal growth factor receptor, the target of cetuximab, is overexpressed in gastric cancer (Gamboa-Dominguez et al, 2004; Dragovich et al, 2006). Overexpression of EGFR has, in some studies, been associated with a poor prognosis underlining the significant role EGFR may have in human gastric cancer biology. Therefore, it was considered of value to investigate cetuximab in combination with platinumbased combination therapy in patients with advanced gastric cancer. The weekly FUFOX regimen was regarded as an appropriate chemotherapy backbone regimen, as a previous phase II multicentre trial had shown encouraging activity of FUFOX in patients with metastatic gastric cancer (Lordick et al, 2005).

The design of this phase II study defined an overall response rate (partial and complete responses) of $30-50 \%$ as expected and of $50 \%$ or more as being worth further investigation. Response rates of the established chemotherapy doublet regimens used in comparable patient populations have been reported to be below $30 \%$ in randomised trials, for example: $20 \%$ for cisplatinum and 5 -FU in an EORTC study (Vanhoefer et al, 2000) and 25\% for cisplatin plus 5-fluororacil in the randomised TAX325 study (Van Cutsem et al, 2006). Response rates for chemotherapy triplets have been reported to be above $30 \%$ but below $50 \%$, for example $46 \%$ for epirubicine plus cisplatin and 5-fluorouracil (Waters et al, 1999) and 37\% for docetaxel plus cisplatin and 5-fluorouracil (Van Cutsem et al, 2006). Therefore, we felt that an expected response rate of $30-50 \%$ for a chemotherapy doublet plus one biologically targeted agent ('new triplet') is an adequate assumption. A response rate of $>50 \%$ (alternative hypothesis) would be of particular interest for further phase III testing of the new drug.

Treatment with cetuximab plus FUFOX-induced objective tumour responses in $65 \%$ of treated patients, which was clearly above the threshold for accepting the alternative hypothesis. It was also $10 \%$ higher than the overall response rate that had been observed in the previous FUFOX alone study (Lordick et al, 2005). This comparison allows the cautious conclusion that cetuximab may increase the activity of chemotherapy with a platinum compound plus a fluoropyrimidine in advanced gastric cancer. 
Our findings are in line with the results obtained by other groups who have studied cetuximab in advanced gastric cancer. Pinto et al (2007) were the first to study cetuximab in combination with irinotecan and 5-fluorouracil in this setting and recorded a response rate of $44 \%$ with a $95 \%$ CI ranging from 28 to $61 \%$, thus indicating the substantial activity of this regimen. The same authors recently published the results of a phase II study combining cetuximab with cisplatin and docetaxel in advanced gastric cancer (Pinto et al, 2009). The observed objective response rate of $41 \%$ (95\% CI, 29-53) was judged to be higher than with cisplatin and docetaxel alone. The TTP in Pinto's first study was particularly interesting as it approached a median of 8 months, which is longer than that achieved with irinotecan and 5-fluorouracil alone (Pozzo et al, 2004; Dank et al, 2008). These results are supported by the current study in which the median TTP was found to be 7.6 months. A shorter TTP of median 5.5 months, together with a noteworthy response rate of $50 \%$, was reported in the first cetuximab-chemotherapy study published from East Asia (Han et al, 2009).

The potentially enhanced anti-tumoural effects of chemotherapy when combined with cetuximab in gastric cancer seen in these clinical trials are not unexpected, given that data from preclinical trials in EGFR-expressing gastric cancer cell lines and tumour xenografts suggested an anti-tumour effect of cetuximab as a result of different intracellular and immunological mechanisms (Hara et al, 2008; Shimura et al, 2008; Patel et al, 2009). Moreover, one recently described mechanism of resistance against cetuximab, that is the activating mutation of the KRAS gene, seems to have a very low prevalence in gastric cancer (Kim et al, 2003; Lee et al, 2003; Zhao et al, 2004). This finding has been confirmed in the current study, wherein a KRAS mutation was found in only one tumour sample.

This study revealed that cetuximab plus FUFOX is a feasible regimen associated with the generally manageable toxicity. However, the rate and the severity of observed side effects and adverse events were higher than that reported with FUFOX alone. The incidence of diarrhoea ( $33 \%$ grade $3 / 4$ ), in particular, seemed to be increased with the addition of cetuximab and the different phenotypes of skin toxicities (24\% grade $3 / 4)$ associated with the use of anti-EGFR-directed drugs must also be taken into consideration. The patients enrolled in this trial presented with a high tumour load. All patients had metastatic disease, no patients with locally advanced tumours were included, and almost $50 \%$ had more than two organ systems involved. Compared with other phase II studies like the FUFOX alone study published previously (Lordick et al, 2005), patients presented with a poorer performance status and many had been pretreated with adjuvant chemotherapy. The poorer performance status and more advanced disease status of patients included in this study is also reflected by the 60-day mortality rate of $10 \%$ that was higher than in previously reported phase II trials of the same group of authors (Lordick et al, 2005; Lorenzen et al, 2007). This may explain the short duration of treatment in a considerable number of patients. Tragically, one patient died because of the sequelae of a severe infusion-related drug reaction occurring during the first infusion of cetuximab. This appalling event underlines the necessity of prophylactic premedication with corticosteroids and antihistamines in patients undergoing the first infusion with cetuximab and the unconditional need for continuous cardiorespiratory monitoring and direct observation.

New biologically targeted agents are currently being investigated in gastric cancer. The results of this study, together with Pinto et al's study published previously, encouraged us to initiate a randomised, multinational, phase III study to investigate the value of cetuximab in combination with platinum-fluoropyrimidinechemotherapy in stage IV gastric cancer.

\section{ACKNOWLEDGEMENTS}

We thank the team from Merck Darmstadt, Germany and Tobias Lehmacher in particular and the team from Sanofi-Aventis, Germany for their financial support of this investigator-initiated trial and the provision with study drugs.

This investigator-initiated trial was sponsored by the Technische Universität München, Munich, Germany. An unrestricted grant and drug support was provided by Merck Darmstadt KgaA Germany and by Sanofi-Aventis GmbH Germany.

\section{Conflict of interest}

Florian Lordick has received research support and lecture honoraria from Merck Darmstadt KgaA and from Sanofi-Aventis.

\section{REFERENCES}

Al-Batran SE, Hartmann JT, Probst S, Schmalenberg H, Hollerbach S, Hofheinz R, Rethwisch V, Seipelt G, Homann N, Wilhelm G, Schuch G, Stoehlmacher J, Derigs HG, Hegewisch-Becker S, Grossmann J, Pauligk C, Atmaca A, Bokemeyer C, Knuth A, Jäger E (2008) Phase III trial in metastatic gastroesophageal adenocarcinoma with fluorouracil, leucovorin plus either oxaliplatin or cisplatin: a study of the Arbeitsgemeinschaft Internistische Onkologie. J Clin Oncol 26: 1435-1442

Amado RG, Wolf M, Peeters M, Van Cutsem E, Siena S, Freeman DJ, Juan T, Sikorski R, Suggs S, Radinsky R, Patterson SD, Chang DD (2008) Wild-type KRAS is required for panitumumab efficacy in patients with metastatic colorectal cancer. J Clin Oncol 26: 1626-1634

Bokemeyer C, Bondarenko I, Makhson A, Hartmann JT, Aparicio J, de Braud F, Donea S, Ludwig H, Schuch G, Stroh C, Loos AH, Zubel A, Koralewski P (2009) Fluorouracil, leucovorin, and oxaliplatin with and without cetuximab in the first-line treatment of metastatic colorectal cancer. J Clin Oncol 27: 663-671

Bonner JA, Harari PM, Giralt J, Azarnia N, Shin DM, Cohen RB, Jones CU, Sur R, Raben D, Jassem J, Ove R, Kies MS, Baselga J, Youssoufian H, Amellal N, Rowinsky EK, Ang KK (2006) Radiotherapy plus cetuximab for squamous-cell carcinoma of the head and neck. $N$ Engl J Med 354: $567-578$

Brink M, de Goeij AF, Weijenberg MP, Roemen GM, Lentjes MH, Pachen MM, Smits KM, de Bruïne AP, Goldbohm RA, van den Brandt PA (2003)

K-ras oncogene mutations in sporadic colorectal cancer in The Netherlands Cohort Study. Carcinogenesis 24: 703-710

Ciardiello F, Tortora G (2008) EGFR antagonists in cancer treatment. $N$ Engl J Med 358: $1160-1174$

Cunningham D, Humblet Y, Siena S, Khayat D, Bleiberg H, Santoro A, Bets D, Mueser M, Harstrick A, Verslype C, Chau I, Van Cutsem E (2004) Cetuximab monotherapy and cetuximab plus irinotecan in irinotecanrefractory metastatic colorectal cancer. $N$ Engl J Med 351: $337-345$

Cunningham D, Starling N, Rao S, Iveson T, Nicolson M, Coxon F, Middleton G, Daniel F, Oates J, Norman AR, Upper Gastrointestinal Clinical Studies Group of the National Cancer Research Institute of the United Kingdom (2008) Capecitabine and oxaliplatin for advanced esophagogastric cancer. $N$ Engl J Med 358: 36-46

Dank M, Zaluski J, Barone C, Valvere V, Yalcin S, Peschel C, Wenczl M, Goker E, Cisar L, Wang K, Bugat R (2008) Randomized phase III study comparing irinotecan combined with 5 -fluorouracil and folinic acid to cisplatin combined with 5-fluorouracil in chemotherapy naive patients with advanced adenocarcinoma of the stomach or esophagogastric junction. Ann Oncol 19: 1450-1457

Dragovich T, McCoy S, Fenoglio-Preiser CM, Wang J, Benedetti JK, Baker AF, Hackett CB, Urba SG, Zaner KS, Blanke CD, Abbruzzese JL (2006) Phase II trial of erlotinib in gastroesophageal junction and gastric adenocarcinomas: SWOG 0127. J Clin Oncol 24: 4922-4927 
Gamboa-Dominguez A, Dominguez-Fonseca C, Quintanilla-Martinez L, Reyes-Gutierrez E, Green D, Angeles-Angeles A, Busch R, Hermannstädter C, Nährig J, Becker KF, Becker I, Höfler H, Fend F, Luber B (2004) Epidermal growth factor receptor expression correlates with poor survival in gastric adenocarcinoma from Mexican patients: a multivariate analysis using a standardized immunohistochemical detection system. Mod Pathol 17: 579-587

Han SW, Oh DY, Im SA, Park SR, Lee KW, Song HS, Lee NS, Lee KH, Choi IS, Lee MH, Kim MA, Kim WH, Bang YJ, Kim TY (2009) Phase II study and biomarker analysis of cetuximab combined with modified FOLFOX6 in advanced gastric cancer. Br J Cancer 100: $298-304$

Hara M, Nakanishi H, Tsujimura K, Matsui M, Yatabe Y, Manabe T, Tatematsu M (2008) Interleukin-2 potentiation of cetuximab antitumor activity for epidermal growth factor receptor-overexpressing gastric cancer xenografts through antibody-dependent cellular cytotoxicity. Cancer Sci 99: $1471-1478$

Kamangar F, Dores GM, Anderson WF (2006) Patterns of cancer incidence, mortality, and prevalence across five continents: defining priorities to reduce cancer disparities in different geographic regions of the world. J Clin Oncol 24: 2137-2150

Karapetis CS, Khambata-Ford S, Jonker DJ, O'Callaghan CJ, Tu D, Tebbutt NC, Simes RJ, Chalchal H, Shapiro JD, Robitaille S, Price TJ, Shepherd L, $\mathrm{Au}$ HJ, Langer C, Moore MJ, Zalcberg JR (2008) K-ras mutations and benefit from cetuximab in advanced colorectal cancer. N Engl J Med 359: $1757-1765$

Kim IJ, Park JH, Kang HC, Shin Y, Park HW, Park HR, Ku JL, Lim SB, Park JG (2003) Mutational analysis of BRAF and K-ras in gastric cancers: absence of BRAF mutations in gastric cancers. Hum Genet 114: 118-120

Lee SH, Lee JW, Soung YH, Kim HS, Park WS, Kim SY, Lee JH, Park JY, Cho YG, Kim CJ, Nam SW, Kim SH, Lee JY, Yoo NJ (2003) BRAF and KRAS mutations in stomach cancer. Oncogene 22: 6942-6945

Lordick F, Lorenzen S, Stollfuss J, Vehling-Kaiser U, Kullmann F, Hentrich M, Zumschlinge R, Dietzfelbinger H, Thoedtmann J, Hennig M, Seroneit T, Bredenkamp R, Duyster J, Peschel C (2005) Phase II study of weekly oxaliplatin plus infusional fluorouracil and folinic acid (FUFOX regimen) as first-line treatment in metastatic gastric cancer. Br J Cancer 93: 190 - 194

Lorenzen S, Hentrich M, Haberl C, Heinemann V, Schuster T, Seroneit T, Roethling N, Peschel C, Lordick F (2007) Split-dose docetaxel, cisplatin and leucovorin/fluorouracil as first-line therapy in advanced gastric cancer and adenocarcinoma of the gastroesophageal junction: results of a phase II trial. Ann Oncol 18: 1673-1679

Martinelli E, De Palma R, Orditura M, De Vita F, Ciardiello F (2009) Antiepidermal growth factor receptor monoclonal antibodies in cancer therapy. Clin Exp Immunol 158: 1-9

Patel D, Bassi R, Hooper A, Prewett M, Hicklin DJ, Kang X (2009) Antiepidermal growth factor receptor monoclonal antibody cetuximab inhibits EGFR/HER-2 heterodimerization and activation. Int J Oncol 34: $25-32$

Pinto C, Di Fabio F, Siena S, Cascinu S, Rojas Llimpe FL, Ceccarelli C, Mutri V, Giannetta L, Giaquinta S, Funaioli C, Berardi R, Longobardi C, Piana E, Martoni AA (2007) Phase II study of cetuximab in combination with FOLFIRI in patients with untreated advanced gastric or gastroesophageal junction adenocarcinoma (FOLCETUX study). Ann Oncol 18: 510-517

Pinto C, Di Fabio F, Barone C, Siena S, Falcone A, Cascinu S, Rojas Llimpe FL, Stella G, Schinzari G, Artale S, Mutri V, Giaquinta S, Giannetta L,
Bardelli A, Martoni AA (2009) Phase II study of cetuximab in combination with cisplatin and docetaxel in patients with untreated advanced gastric or gastro-oesophageal junction adenocarcinoma (DOCETUX study). Br J Cancer 101: 1261-1268

Pozzo C, Barone C, Szanto J, Padi E, Peschel C, Bükki J, Gorbunova V, Valvere V, Zaluski J, Biakhov M, Zuber E, Jacques C, Bugat R (2004) Irinotecan in combination with 5-fluorouracil and folinic acid or with cisplatin in patients with advanced gastric or esophageal-gastric junction adenocarcinoma: results of a randomized phase II study. Ann Oncol 15: $1773-1781$

Shimura T, Kataoka H, Ogasawara N, Kubota E, Sasaki M, Tanida S, Joh T (2008) Suppression of proHB-EGF carboxy-terminal fragment nuclear translocation: a new molecular target therapy for gastric cancer. Clin Cancer Res 14: 3956-3965

Therasse P, Arbuck SG, Eisenhauer EA, Wanders J, Kaplan RS, Rubinstein L, Verweij J, Van Glabbeke M, van Oosterom AT, Christian MC, Gwyther SG (2000) New guidelines to evaluate the response to treatment in solid tumors. European Organization for Research and Treatment of Cancer, National Cancer Institute of the United States, National Cancer Institute of Canada. J Natl Cancer Inst 92: 205-216

Van Cutsem E, Moiseyenko VM, Tjulandin S, Majlis A, Constenla M, Boni C, Rodrigues A, Fodor M, Chao Y, Voznyi E, Risse ML, Ajani JA, V325 Study Group (2006) Phase III study of docetaxel and cisplatin plus fluorouracil compared with cisplatin and fluorouracil as first-line therapy for advanced gastric cancer: a report of the V325 Study Group. J Clin Oncol 24: 4991 - 4997

Van Cutsem E, Kohne CH, Hitre E, Zaluski J, Chang Chien CR, Makhson A, D’Haens G, Pintér T, Lim R, Bodoky G, Roh JK, Folprecht G, Ruff P, Stroh C, Tejpar S, Schlichting M, Nippgen J, Rougier P (2009) Cetuximab and chemotherapy as initial treatment for metastatic colorectal cancer. $N$ Engl J Med 360: 1408-1417

Vanhoefer U, Rougier P, Wilke H, Ducreux MP, Lacave AJ, Van Cutsem E, Planker M, Santos JG, Piedbois P, Paillot B, Bodenstein H, Schmoll HJ, Bleiberg H, Nordlinger B, Couvreur ML, Baron B, Wils JA (2000) Final results of a randomized phase III trial of sequential high-dose methotrexate, fluorouracil, and doxorubicin versus etoposide, leucovorin, and fluorouracil versus infusional fluorouracil and cisplatin in advanced gastric cancer: A trial of the European Organization for Research and Treatment of Cancer Gastrointestinal Tract Cancer Cooperative Group. J Clin Oncol 18: 2648-2657

Vermorken JB, Mesia R, Rivera F, Remenar E, Kawecki A, Rottey S, Erfan J, Zabolotnyy D, Kienzer HR, Cupissol D, Peyrade F, Benasso M, Vynnychenko I, De Raucourt D, Bokemeyer C, Schueler A, Amellal N, Hitt R (2008) Platinum-based chemotherapy plus cetuximab in head and neck cancer. $N$ Engl J Med 359: 1116-1127

Wagner AD, Grothe W, Haerting J, Kleber G, Grothey A, Fleig WE (2006) Chemotherapy in advanced gastric cancer: a systematic review and meta-analysis based on aggregate data. J Clin Oncol 24: 2903-2909

Waters JS, Norman A, Cunningham D, Scarffe JH, Webb A, Harper P, Joffe JK, Mackean M, Mansi J, Leahy M, Hill A, Oates J, Rao S, Nicolson M, Hickish T (1999) Long-term survival after epirubicin, cisplatin and fluorouracil for gastric cancer: results of a randomized trial. Br J Cancer 80: $269-272$

Zhao W, Chan TL, Chu KM, Chan AS, Stratton MR, Yuen ST, Leung SY (2004) Mutations of BRAF and KRAS in gastric cancer and their association with microsatellite instability. Int J Cancer 108: 167-169 